\title{
Operational modal analysis of road-rail bridge
}

\author{
M. Cardoso ${ }^{1}$, R. A. C. Sampaio ${ }^{1, a}$, R. M. de Souza ${ }^{1,2}$ and E. Silva ${ }^{2,3}$ \\ ${ }^{1}$ Federal University of Pará, Department of Civil Engineering Pará, Brazil. \\ ${ }^{2}$ Dynamis Techne, Pará, Brazil. \\ ${ }^{3}$ Federal University of Rio de Janeiro, Civil Engineering program- COOPE, Rio de Janeiro,RJ,Brazil.
}

\begin{abstract}
In this paper, we describe an Operational Modal Analysis (OMA) of the Bridge over the Tocantins River, a composite road-rail bridge located in the city of Marabá, state of Pará, northern Brazil. The bridge is part of the Carajás Railway, which is used by VALE Company to transport iron ore from "Serra dos Carajás", the largest mineral reserve of the planet. The bridge has a length of $2310 \mathrm{~m}$, being the second longest road-rail bridge in Brazil. The study focused on the bridge central span (with $77 \mathrm{~m}$ of length) and two adjacent spans (with $44 \mathrm{~m}$ of length). We employed Piezo-electric accelerometers to measure the dynamic response of the bridge under ambient excitation, which consisted of the passage of loaded and unloaded trains, road traffic, wind and river current. For modal identification, to avoid the influence of the train mass over the bridge system, we only considered acceleration signals of road traffic and signals corresponding to intervals after the passage of loaded trains, i.e., the study disregarded the intervals during which the trains were over the monitored spans. We obtained modal parameters through two identification methods: one in the time domain and other in the frequency domain. We also performed a comparative analysis between the experimental modal parameters, and the numerical results obtained with a finite element model provided by a third-part company.
\end{abstract}

\section{Introduction}

Bridges are structures susceptible to dynamic problems, mainly produced by vehicles and wind. Due to the transient nature of these loads, the resulting responses are dynamic in nature. Thus, to understand the behavior of these structures under its usual loading conditions, it is essential to perform a modal analysis to obtain its natural frequencies, modal shapes and damping capacity. These properties directly relates to the structural integrity of a bridge, since occurrence of damage causes changes in these parameters.

This study is part of a broader study conducted by Dynamis Techne [1], involving both fatigue/stress and vibration experimental analysis of the Bridge over the Tocantins River. The objective of the present work was to determine, through vibration records measured on the bridge, the dynamic characteristics of the structure. With this purpose, we used identification methods in the time domain and the frequency domain implemented in software Artemis [2].

\section{Structure Description}

The bridge over the Tocantins River is located in the Carajás Railroad, in the state of Pará - Northern Brazil (Figure 1). It has a total length of $2310 \mathrm{~m}$ and width of $19.40 \mathrm{~m}$. The structural system consists of prestressed concrete deck slabs, carrying the rail and road traffic, on top of steel girders. Hollow reinforced concrete columns on top of concrete piles form the substructure. The study was carried out in the central part of the bridge between columns 20 and 23, which consists of two spans $44 \mathrm{~m}$

\footnotetext{
$\overline{{ }^{a} \text { Corresponding author: rsampaio@ }}$ ufpa.br
}

long and one central span $77 \mathrm{~m}$ long, which is partially supported on a steel arch, as shown in Figure 1.

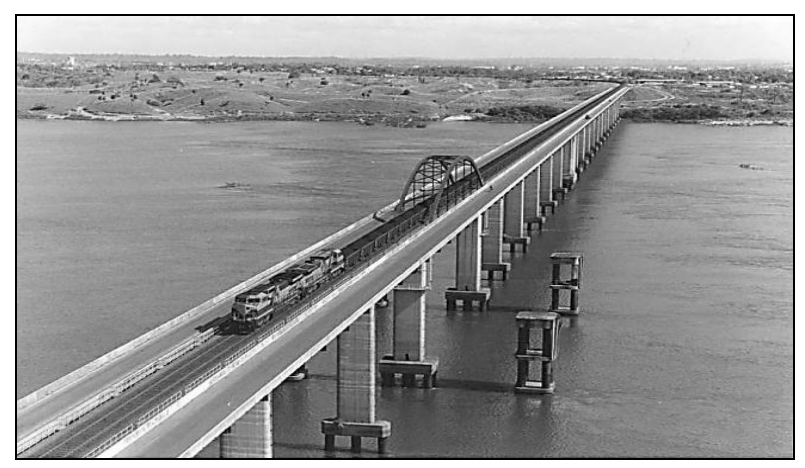

Figure 1. Bridge over Tocantins River - aerial view

\section{Experimental Modal Analysis}

\subsection{Test Setup}

For the bridge instrumentation, we used 32 low frequency piezoelectric accelerometers (Wilcoxon - model 793L), and data acquisition system Lynx ADS 2000. The accelerometer positions were determined considering the analysis of a numerical model developed by a third-part company, and taking accessibility into account. Figure 2 schematically presents the test setup of the monitored structure. This figure also shows the six sections along the spans and the two sections at columns P20 and P21, where the accelerometers were positioned. 


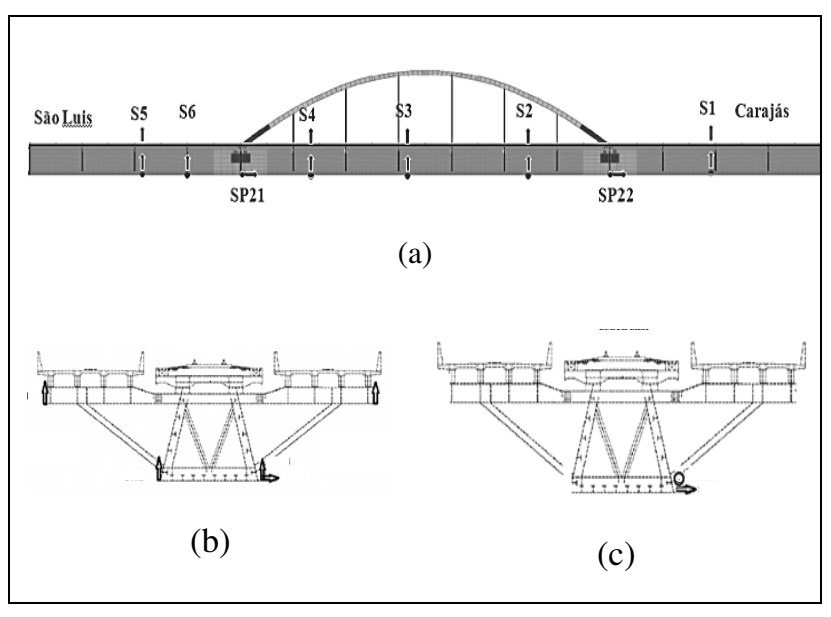

Figure 2. (a) Monitored sections. (b) Accelerometer position section along the span and (c) Accelerometer position - section on the columns

\subsection{Dynamic Test}

We performed dynamic tests under ambient vibration, using the following excitation source: wind, river current, passage of loaded and unloaded trains, as well as road traffic.

The trains that operate on this railway are hauled by three diesel-electric locomotives (with 6 axles, and 300 $\mathrm{kN}$ per axle) and have 330 freight cars (with 4 axles, and $325 \mathrm{kN}$ per axle when loaded, and $52.5 \mathrm{kN}$ per axle when unloaded). The acceleration time histories resulting from the passage of loaded trains are not a reliable means for obtaining the dynamic characteristics of the bridge itself, since the bridge-train system and the bridge itself have different modal parameters. This happens because the mass of the loaded trains is very high, having a great influence on the total mass of the system. For this reason, in the present study, we performed system modal identification using the following types of recorded signals: 1) acceleration records during the passage of road traffic only; 2) acceleration records immediately after the passage of loaded trains.

It is worth mentioning that, in the acceleration records obtained right after the passage of the loaded trains, there is also the vibration provided by the road traffic (trucks, automobiles, etc), since the road traffic could not be interrupted to perform the monitoring tests.

Thus, we used two acceleration records corresponding to road traffic and two records corresponding to the time interval after the passage of loaded trains. The first test record corresponding to road traffic has a duration of 6 $\mathrm{min}$ and the second test record has a duration of $41.5 \mathrm{~min}$. Concerning the tests corresponding to the interval after the passage of the loaded trains, the duration of the first record is $4.5 \mathrm{~min}$ and the duration of the second record is $2.5 \mathrm{~min}$

We could observe that, despite the records concerting the time interval after loaded trains have a shorter acquisition time when compared with records during road traffic, the spectral series were very similar. However, the spectrum obtained from the records after the loaded train passage showed well-defined peaks.

\subsection{Modal Identification}

We performed the modal identification analysis using stochastic modal identification methods. The stochastic analysis is divided into two types: the analysis in the time domain and in the frequency domain. The time domain method that we used was the "Stochastic Subspace Identification - unweighted main component" method (SSI-UPC), and the frequency domain method was the "Enhanced Free Domain Decomposition" method (EFDD). These two methods are implemented in the commercial software Artemis [1], which was used for processing the analyses.

We evaluated some analysis parameters were evaluated in order to find the largest amount of physical modes. These parameters are listed below:

a) Decimation factor: decimation is a process that reduces the sampling frequency of the problem, allowing the amplification of the response in a particular frequency band. The Artemis program uses an 8th order Chebyshev anti-aliasing filter. The used sampling frequency was 400 $\mathrm{Hz}$, i.e., corresponding to a Nyquist frequency of $200 \mathrm{~Hz}$, and, we used a decimation factor of 10 , to obtain a new Nyquist frequency of $20 \mathrm{~Hz}$. It is important to note that only the modal characteristics corresponding to the frequencies from 0 to $80 \%$ of the new Nyquist frequency are safe to be used, since frequencies above this range may contain errors caused by aliasing.

b) Model order: The increase in model order allows the expansion of the number of modes identified in the same frequency range. However, higher values of model order causes a higher processing time. Thus, the model order was increased from 100 until it stopped producing significant changes in the identified modal characteristics. For the records obtained with road traffic, the maximum employed model order was 180 , and for the records obtained after the passage of the loaded train, the highest model order was 160 .

c) Projection Channels: As mentioned by Herlufsen apud [5], in the case where many sensors are used simultaneously, the parametric model fit in SSI analysis suffers from the estimation of many noise modes, compared to the number of physical modes of the system. The main reason for this problem is that the many channels contain the same physical information but different random errors. The use of projection channels decreases the amount of redundant information and the estimated models tends to stabilize faster, i.e. at lower state space dimensions (model order). Nguyen et al apud [5] also observed that some modes can be mistakenly detected as noise if the channel projection is not used. In this particular case, analyses were made with three (the minimum allowed), 4 and 5 projection channels, and comparison among the corresponding results were 
performed. The test results showed that the use of 4 projection channels was appropriate.

\section{Results}

\subsection{Experimental Modal Analysis}

Among the detected modes found, only those with welldefined mode shapes were selected, i.e., we only selected experimental modes that seemed feasible possible to correspond to actual vibration modes of the structure. Table 1 shows the modes with their respective properties identified in each test.

The results of the modal identification analysis were very similar for each test, in terms of quantity of identified modes and modal shape, except for the first test under road traffic, for which we detected fewer modes. One should observe that this test has a much shorter acquisition time (6 min) than the second test $(41.5 \mathrm{~min})$. Thus, from these results, one can infer the influence of record time on the quality of the modal identification. However, the modal identification quality is also associated with the amplitude and quality of the obtained signal. For the tests performed after the passage of loaded trains, the recording time is between 2 and $5 \mathrm{~min}$, but their records have a greater amplitude of vibration and the number of detected modes in these cases was equivalent to the second test with road traffic. It is also worth mentioning that we could identify a larger number of modes with the SSI method than with the EFDD method.

The fact that the bridge under study is a road-rail bridge has facilitated the identification of modes, i.e., if the bridge were just a railway-bridge, perhaps the number of physical excited modes were lower.

\subsection{Comparison between the experimental and computational results}

A finite element model was developed with software SAP2000 [6] by a third-part engineering company, to perform static analysis of the bridge. The main structural components were modelled with shell and frame elements, and the support system (bearers, piers, foundations) was represented by spring elements, as shown in Figure 3.

To complement the analysis performed in this study, the dynamic properties identified in the experimental modal analysis were compared with the results of the computational modal analysis. We made this comparison in order to verify the validity of the model to represent the behaviour of the real structure, as well as, the possibility of using this model to perform dynamic analysis.

The similarity between the experimental and numerical mode shapes was verified by visual analysis of the mode shapes and also through the Modal Assurance Criterium (MAC). We observed that most of the MAC values varied around 0.7 .

Table 2 presents the MAC values for the identified modes and Figure 4 shows the comparison between the
1 st experimental mode and the 10th numerical mode. The lower MAC values (0.53 and 0.63) were found when comparing the 5 th experimental mode shape, determined with the records after the passage of the loaded train, and the 21 st numerical mode shape. However, when the same numerical mode (5th mode) is compared with the corresponding experimental mode $\left(21^{\text {st }}\right.$ mode) obtained with the road traffic records, the MAC values are 0.85 and 0.81 , as it can be observed in Table 2 .

We verified the correlation between frequencies, by calculating the relative error between them, in order to evaluate the difference of the numeric frequency (fnum) compared to experimental frequencies $($ fexp).

It should be emphasized that we determined the experimental modes always using more than one method. In view of this, we used a mean frequency to represent each of these modes, as shown in Table 4.

One should note that the difference between the numerical and experimental frequencies is very large for the first two identified modes. There is an inversion in the sequence of the frequencies, i.e., the first experimental vertical mode $(2.46 \mathrm{~Hz})$ corresponds to the second computational lateral mode $(2.40 \mathrm{~Hz})$; and the second experimental mode $(3 \mathrm{~Hz})$ corresponds to the first vertical mode obtained numerically $(3.59 \mathrm{~Hz})$, as can be seen in Table 4. For the other frequencies identified, the difference is smaller, but still indicates a need for adjustment of the numerical model.

\section{Conclusions}

The present study indicates the importance of vibration amplitude and time record in the to identification of the dynamic characteristics of structures this type of structure, as well as the significance of the choice of stochastic method used in the analysis. In addition, the study reveals the significance of and the use of certain features to achieve more accurate results in modal identification, such asas decimation, projection channels and model order for modal identification. Regarding the verification of the proposed numerical model, it was possible to verify that the differences between the experimental and numerical frequencies are large, including reversal of the first modes. Thus, it can be said that the numerical model requires adjustments to better represent the dynamic behaviour of the bridge.

\section{Acknowledgments}

The authors acknowledge VALE company for providing the means for the development of this work, and Beton Stahl Company for providing the numerical model of the bridge. The authors also wish to specially acknowledge the following field team members: André Felipe de Queiroz, Adriano Pinto, Douglas de Oliveira and Basílio Leandro Silva. 
Table 1. Identified Modal parameters.

\begin{tabular}{|c|c|c|c|c|c|}
\hline Mode & $\begin{array}{c}\text { Vibration after } \\
\text { loaded train } \\
\text { passage } 1\end{array}$ & $\begin{array}{c}\text { Vibration after } \\
\text { loaded train } \\
\text { passage } 2\end{array}$ & Road traffic 1 & Road traffic 2 & Schematic mode shape \\
\hline \multirow{4}{*}{1} & $2,51 \mathrm{~Hz}(\mathrm{SSI})$ & $2,53 \mathrm{~Hz}(\mathrm{SSI})$ & $2,51 \mathrm{~Hz}(\mathrm{SSI})$ & $2,51 \mathrm{~Hz}(\mathrm{SSI})$ & \multirow{4}{*}{ i. } \\
\hline & $\zeta=1,74 \%$ & $\zeta=0,84 \%$ & $\zeta=0,63 \%$ & $\zeta=0,96 \%$ & \\
\hline & $2,52 \mathrm{~Hz}$ (EFDD) & $2,47 \mathrm{~Hz}$ (EFDD) & $2,08 \mathrm{~Hz}$ (EFDD) & $2,52 \mathrm{~Hz}$ (EFDD) & \\
\hline & $\zeta=0,61 \%$ & $\zeta=0,71 \%$ & $\zeta=0,53 \%$ & $\zeta=0,98 \%$ & \\
\hline \multirow{4}{*}{2} & $3,03 \mathrm{~Hz}$ (SSI) & $3,00 \mathrm{~Hz}$ (SSI) & $2,99 \mathrm{~Hz}$ (SSI) & $2,99 \mathrm{~Hz}$ (SSI) & \\
\hline & $\zeta=0,99 \%$ & $\zeta=0,91 \%$ & $\zeta=1,45 \%$ & $\zeta=1,03 \%$ & \\
\hline & $3,02 \mathrm{~Hz}$ (EFDD) & $3,01 \mathrm{~Hz}$ (EFDD) & $3,01 \mathrm{~Hz}$ (EFDD) & $3,0 \mathrm{~Hz}$ (EFDD) & \\
\hline & $\zeta=1,13 \%$ & $\zeta=1,57 \%$ & $\zeta=1,29 \%$ & $\zeta=1,12 \%$ & \\
\hline \multirow{4}{*}{3} & $3,71 \mathrm{~Hz}(\mathrm{SSI})$ & $3,79 \mathrm{~Hz}$ (SSI) & & $3,68 \mathrm{~Hz}(\mathrm{SSI})$ & \\
\hline & $\zeta=4,03 \%$ & $\zeta=4,68 \%$ & & $\zeta=3,22 \%$ & \\
\hline & $3,62 \mathrm{~Hz}$ (EFDD) & & & $3,67 \mathrm{~Hz}$ (EFDD) & \\
\hline & $\zeta=0,46 \%$ & & & $\zeta=1,22 \%$ & \\
\hline \multirow{4}{*}{4} & $4,65 \mathrm{~Hz}(\mathrm{SSI})$ & $4,61 \mathrm{~Hz}(\mathrm{SSI})$ & $4,64 \mathrm{~Hz}(\mathrm{SSI})$ & $4,63 \mathrm{~Hz}(\mathrm{SSI})$ & \multirow{4}{*}{ 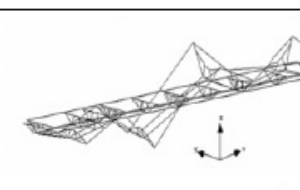 } \\
\hline & $\zeta=0,96 \%$ & $\zeta=1,45 \%$ & $\zeta=1,09 \%$ & $\zeta=1,2 \%$ & \\
\hline & 4,67Hz (EFDD) & $4,55 \mathrm{~Hz}$ (EFDD) & & $4,63 \mathrm{~Hz}$ (EFDD) & \\
\hline & $\zeta=1,16 \%$ & $\zeta=0,23 \%$ & & $\zeta=0,44 \%$ & \\
\hline \multirow{3}{*}{5} & $6,7 \mathrm{~Hz}(\mathrm{SSI})$ & $6,74 \mathrm{~Hz}(\mathrm{SSI})$ & $6,72 \mathrm{~Hz}(\mathrm{SSI})$ & $6,72 \mathrm{~Hz}(\mathrm{SSI})$ & \multirow{3}{*}{68 . } \\
\hline & $\zeta=0,79 \%$ & $\zeta=0,65 \%$ & $\zeta=0,65 \%$ & $\zeta=1,03 \%$ & \\
\hline & & & & & \\
\hline
\end{tabular}

Table 2 Comparison of MAC values for Experimental and numerical mode shapes.

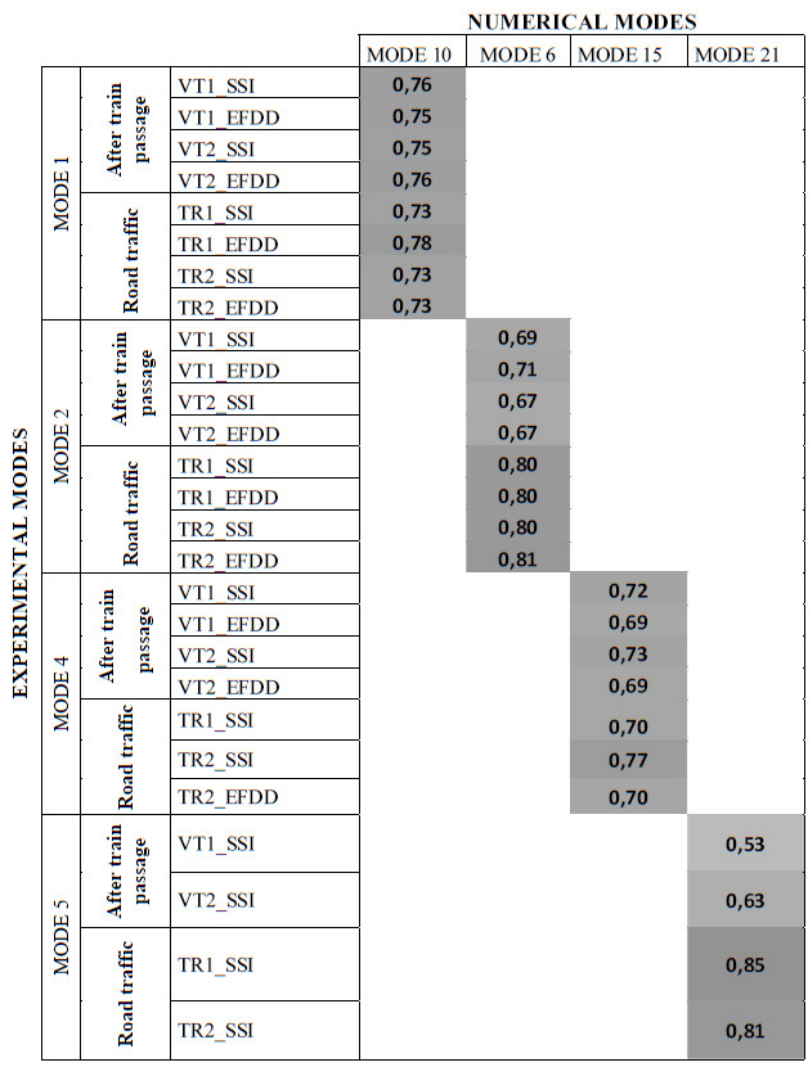

Table 3 Differences between numerical and experimental frequency values for each type of records and method of analysis.

\begin{tabular}{|c|c|c|c|c|c|}
\hline \multicolumn{3}{|c|}{ Experimental } & \multicolumn{3}{|c|}{ Numerical } \\
\hline $\begin{array}{l}\text { Experim. } \\
\text { mode }\end{array}$ & $\begin{array}{l}\text { Mean } \\
\text { freq. }\end{array}$ & $\begin{array}{c}\text { Standard } \\
\text { deviation } \\
(\sigma)\end{array}$ & $\begin{array}{l}\text { Num. } \\
\text { mode }\end{array}$ & Freq. & Vartiation \\
\hline L & $\begin{array}{c}2,46 \\
\text { (vertical) }\end{array}$ & 0,153 & 10 & $\begin{array}{c}3,59 \\
\text { (vertical) }\end{array}$ & $46 \%$ \\
\hline 2 & $\begin{array}{c}3,01 \\
\text { (lateral) }\end{array}$ & 0,011 & 6 & $\begin{array}{c}2,40 \\
\text { (lateral) }\end{array}$ & $20 \%$ \\
\hline 4 & $\begin{array}{c}4,62 \\
\text { (vertical) }\end{array}$ & 0,039 & 15 & $\begin{array}{c}4,97 \\
\text { (vertical) }\end{array}$ & $7,5 \%$ \\
\hline 5 & $\begin{array}{c}6.72 \\
\text { (vertical) }\end{array}$ & 0,017 & 21 & $\begin{array}{c}6,23 \\
\text { (vertical) }\end{array}$ & $7,3 \%$ \\
\hline
\end{tabular}

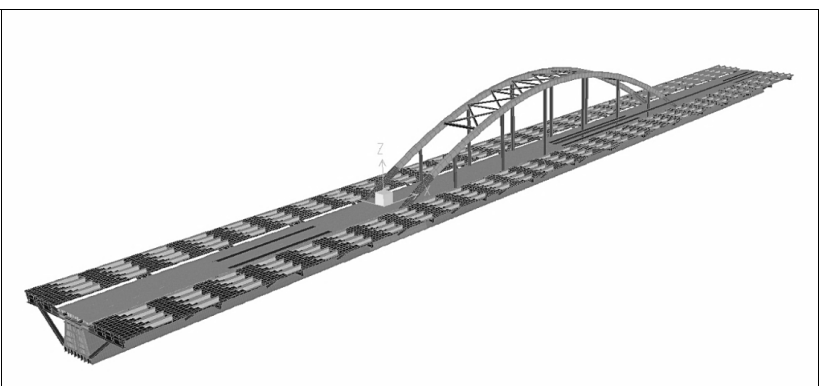

Figure 3 - element finite model - SAP2000 


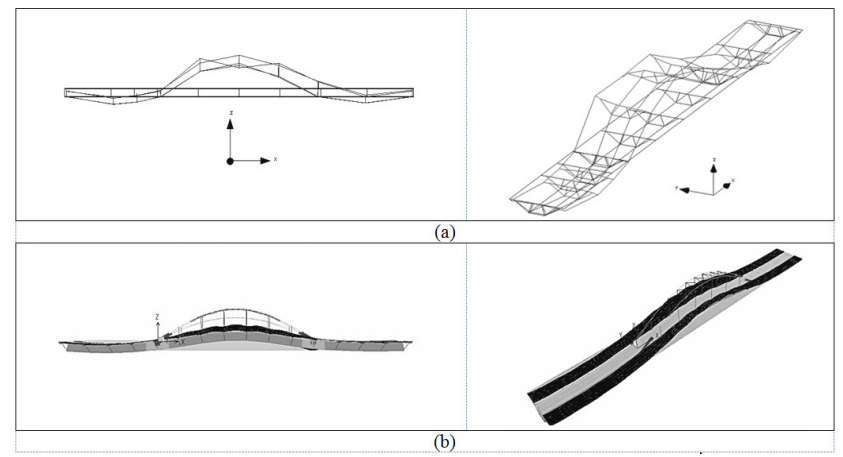

Figure 4 (a) 1st Experimental mode shape. (b) 10th Numerical mode shape

\section{References}

1. DYNAMIS TECHNE. Relatório Técnico. Tratamento dos dados dos acelerômetros e Análise Modal Experimental, Pará (2013)

2. Structural Vibration Solution A/S, ARTeMIS Modal 3.0, NOVI Science Park, Niels Jernes Vej 10, DK-9220 Aalborg East, Denmark; www.svibs.com

3. S. L. A. Lobato, R. A. C Sampaio, J. P. R. Neto, R. L. Queiroz, R. M. Souza, S. D. R. Amador, Análise Modal Experimental de uma ponte metálica ferroviária. In: Construmetal. São Paulo, Brasil (2008).

4. F.Magalhães, E.Caetano, A. Cunha, Desenvolvimento de software em matlab para identificação modal de pontes sob acções ambientais. Universidade do Minho. In: SÍSMICA 2004, $6^{\circ}$ Congresso Nacional de Sismologia e Engenharia Sísmica. Portugal.(2004).

5. R. A. C. SAMPAIO, T. CHAN, Modal Parameters Identification of heavy-haul railway RC bridges - experience acquired. Structural Monitoring and Maintenance: An International Journal. Techno-Press, Austrália. (to be published).

6. SAP2000, Version 15.2.1, CSI Analysis Reference Manual for SAP2000, ETABS, SAFE, and CSiBridge, Computers and Structures, Inc., 2013, Berkeley, CA. 